\title{
Therapeutic properties of a vector carrying the HSV thymidine kinase and GM-CSF genes and delivered as a complex with a cationic copolymer
}

Irina V Alekseenko ${ }^{1,2^{*}}$, Eugene V Snezhkov ${ }^{1}$, Igor P Chernov ${ }^{1}$, Victor V Pleshkan ${ }^{1,2}$, Victor K Potapov ${ }^{1}$, Alexander V Sass ${ }^{1}$, Galina S Monastyrskaya ${ }^{1}$, Eugene P Kopantzev ${ }^{1}$, Tatyana V Vinogradova', Yuri V Khramtsov ${ }^{3}$, Alexey V Ulasov ${ }^{3}$, Andrey A Rosenkranz ${ }^{3,4}$, Alexander S Sobolev ${ }^{3,4}$, Olga A Bezborodova ${ }^{5}$, Anna D Plyutinskaya, Elena R Nemtsova ${ }^{5}$, Raisa I Yakubovskaya ${ }^{5}$ and Eugene D Sverdlov ${ }^{1,2}$

\begin{abstract}
Background: Gene-directed enzyme prodrug therapy (GDEPT) represents a technology to improve drug selectivity for cancer cells. It consists of delivery into tumor cells of a suicide gene responsible for in situ conversion of a prodrug into cytotoxic metabolites. Major limitations of GDEPT that hinder its clinical application include inefficient delivery into cancer cells and poor prodrug activation by suicide enzymes. We tried to overcome these constraints through a combination of suicide gene therapy with immunomodulating therapy. Viral vectors dominate in present-day GDEPT clinical trials due to efficient transfection and production of therapeutic genes. However, safety concerns associated with severe immune and inflammatory responses as well as high cost of the production of therapeutic viruses can limit therapeutic use of virus-based therapeutics. We tried to overcome this problem by using a simple nonviral delivery system.
\end{abstract}

Methods: We studied the antitumor efficacy of a PEI (polyethylenimine)-PEG (polyethylene glycol) copolymer carrying the HSVtk gene combined in one vector with granulocyte-macrophage colony-stimulating factor (GM-CSF) cDNA. The system HSVtk-GM-CSF/PEI-PEG was tested in vitro in various mouse and human cell lines, ex vivo and in vivo using mouse models.

Results: We showed that the HSVtk-GM-CSF/PEI-PEG system effectively inhibited the growth of transplanted human and mouse tumors, suppressed metastasis and increased animal lifespan.

Conclusions: We demonstrated that appreciable tumor shrinkage and metastasis inhibition could be achieved with a simple and low toxic chemical carrier - a PEI-PEG copolymer. Our data indicate that combined suicide and cytokine gene therapy may provide a powerful approach for the treatment of solid tumors and their metastases.

Keywords: Cancer suicide gene therapy, Targeted therapy, Preclinical trials, Metastases, Nonviral vectors, HSVtk, PEG-PEI cationic copolymer, GM-CSF, CMV promoter, Internal ribosome entry site

\footnotetext{
*Correspondence: irina.alekseenko@mail.ru

'Shemyakin-Ovchinnikov Institute of Bioorganic Chemistry, Russian Academy

of Sciences, ul. Miklukho-Maklaya 16/10, Moscow 117997, Russia

${ }^{2}$ Institute of Molecular Genetics, Russian Academy of Sciences, Kurchatov Sa

2, Moscow 123182, Russia

Full list of author information is available at the end of the article
} 


\section{Background}

Chemotherapy, radiotherapy and surgery are conventional treatments for cancer (for recent review, see [1,2]). However, chemotherapy and radiotherapy agents are highly hazardous and, in addition, a majority of cancers have become resistant to current therapeutic options [1,2]. This makes the development of more efficient strategies highly desirable. Various inter- and intracellular barriers to tumor-targeted chemotherapeutic drugs have been considered in detail [3-6].

Great attention was also paid to a strategy of anticancer therapy aimed to potentiate antitumor activity of the immune system [7-12], that looks highly promising.

More than 15 years ago the anticancer armamentarium was extended with gene therapy approaches, the development of which has dramatically accelerated in the recent years (see [13], and for recent reviews [1,2,14-16]). Many approaches to cancer gene therapy have been proposed, and viral and nonviral vectors have been explored. Various strategies of gene therapy have been described (for most recent reviews, see $[1,2]$. One of them (the suicide gene/ prodrug approach or gene directed enzyme prodrug gene therapy, GDEPT) $[1,2,14,17-19]$ is targeted at the systems common to all cancer cells, usually at the replication system. In this regard, this approach resembles chemotherapy with its universal applicability to different types of cancer. However, suicide gene therapy hits its targets from within the cancer cell and is therefore expected to be less toxic to normal cells than classic chemotherapy. GDEPT (other synonyms of this technology see in [19]) is based on the delivery into cancer cells of expressible genes encoding enzymes that can metabolize a separately administered nontoxic prodrug into a cytotoxin. This makes the system much safer than any other known tumor- targeting systems. The generated cytotoxin can not only kill the cancer cell where it was produced but also diffuse into neighboring cells and kill them. This is a so called bystander effect [20-23]. Bystander cell killing may greatly increase the efficiency of GDEPT.

In general, GDEPT looks essentially more powerful than molecular targeted approaches, and recent reports on pre-clinical cancer models demonstrated a high potential of this strategy [1]. Several enzyme-prodrug systems are now in preclinical and clinical trials [1], including the most extensively studied systems of the herpes simplex virus thymidine kinase gene (HSVtk) with ganciclovir (GCV) as a prodrug, and the cytosine deaminase gene $(C D)$ of Escherichia coli or yeast which converts the nontoxic antifungal agent 5-fluorocytosine (5-FC) into toxic 5-fluorouracil (5-FU).

Major limitations of the suicide gene therapy that hinder its clinical application include inefficient delivery to cancer cells (it is also the problem for chemotherapeutic targeting) and poor prodrug activation by suicide enzymes [14]. Some efforts have been and are currently being pursued to increase the activity of individual suicide enzymes towards their respective prodrugs ([24] and refs. therein).

Another way to overcome these constraints might be to combine suicide gene therapy with immunomodulating therapy. Many cytokines activate the immune system, including interleukins (IL) 2, 4, 7, 12 and 18, interferon $\gamma$ (IFN- $\gamma)$, tumor necrosis factor $\alpha(\mathrm{TNF}-\alpha)$, and granulocyte-macrophage colony-stimulating factor (GM-CSF), which are among the most potent inducers of anti-tumor activity in a variety of preclinical studies [25-27]. However, it was reported that effects of cytokines are contradictory and depend on the tumor type and disease stage. Moreover, some cytokines can facilitate malignization of tumors and metastasizing $[28,29]$. Therefore, the choice of cytokines for gene-therapeutic purposes should be based on a thorough analysis of their tests as antitumor agents. Such an analysis indicated that one of the promising candidates was GM-CSF. A comparison of various cytokines showed that GM-CSF enhanced most types of immune responses [30].

It is important that recombinant GM-CSF (Sargramostim) has been extensively used in cancer patients, and its safety is thus well established [31]. Several species of oncolytic viruses were armed with GM-CSF and tested in clinical trials. The trials supported antitumor efficacy of GM-CSF and tumor-specific immune activation [26,31-35]. GMCSF-secreting vaccines for solid tumors demonstrated promising evidence of safety in early phase clinical testing $[36,37]$. An oncolytic adenovirus coexpressing IL-12 and GM-CSF in combination with vaccination demonstrated synergistic antitumor effects [38].

A combination of $H S V t k$ in an adenoviral vector with another vector carrying both the GM-CSF and $I L-2$ genes was tested. The results obtained demonstrated that coexpression of GM-CSF and IL-2 could enhance the effect of HSVtk suicide gene therapy [39]. Other studies also confirmed the efficacy of using IL-2 and GM-CSF in combination with HSVtk in adenoviral vectors [40]. Also, a combination of GM-CSF and HSVtk gene therapy showed a greater therapeutic effect than HSVtk alone $[41,42]$.

However, there is some uncertainty about the use of GM-CSF as an agent for the induction of antitumor immunity [43-45]. GM-CSF may play a key role in the appearance of host immune cells with a suppressive phenotype that poses a significant problem to successful therapy for metastatic cancers [46-48]. To explain the successful antitumor role of GM-CSF in combination with suicide genes, it was suggested that when tumor cells are destroyed and release tumor-specific antigens, GM-CSF in the tumor microenvironment increases antigen uptake and presentation by antigen presenting cells $[31,41]$. 
This hypothesis is in line with the efficient antitumor activity of oncolytic viruses armed with GM-CSF [26,32,49-54]. Therefore, a combination of cancer cell destroying agents with GM-CSF can be a powerful tool for killing cancer and metastasis cells. Up to now, all such combinations used viral vectors that have some limitations in their application to clinical practice $[2,55]$.

To our knowledge, the present study is the first one to test the efficacy of an HSVtk/GM-CSF combination in one vector using a nonviral system (a PEG-PEI copolymer) for its delivery. Nonviral vectors are advantageous over viral vectors due to low immunogenicity, practically unlimited packaging capacity for genetic material, as well as simple and low-cost production [56]. They are used as components of self-assembling complexes with anionic DNA ('polyplexes'). Among cationic polymers, polyethylenimine (PEI) attracts special attention and is the most intensively studied polymer for gene-therapy purposes. The properties and behavior of PEI-containing polyplexes, modified with polyethylene glycol (PEG) and the cell-penetrating peptide TAT, in different cell lines can be adjusted to achieve higher transfection efficiency [57].

Here, the system was tested in vitro in various cell lines, ex vivo, and in vivo on mouse models, and promising results were obtained.

\section{Materials and methods}

\section{Construction of expression plasmids}

The cDNA of the hGM-CSF gene was amplified from plasmid hGM-CSF-pBK, (kindly provided by S. Larin, IGB RAS, Moscow) using primers 5 '-TTATCGATATGTGGC TGCAGAGC and 5'-TTGGATCCTCACTCCTGGACT GG that had at their $5^{\prime}$-ends the restriction sites of ClaI and BamHI, respectively. The amplificate was ligated into pAL-TA vector (Evrogen, Moscow, Russia) containing an SV40 polyA fragment. The hGM-CSF-polyA sequence was excised with $\mathrm{ClaI}$ and SphI and cloned into retroviral vector pFB-neo (Stratagene, La Jolla, USA) that contained a picornavirus internal ribosome entry site (IRES) and was hydrolyzed by these restriction endonucleases. The IREShGM-CSF-polyA cassette was excised from this vector with NotI and BamHI, and its ends were filled in with Klenow fragment. After this, the cassette was blunt-end ligated into CMV-HSVtk-pGL3 vector [58], split at a unique site by $\mathrm{XbaI}$ and treated with Klenow fragment. This gave the construct CMV-HSVtk-hGM-CSF-pGL3 (designated as TKhGM, Figure 1) harboring the HSVtk and hGM-CSF genes under the control of the CMV promoter.

To obtain the construct CMV-HSVtk-mGM-CSF-pGL3 (designated as TKmGM, Figure 1), the mGM-CSF cDNA was amplified with primers $5^{\prime}$-TTATCGATATGTGGCT GCAGAAT and 5' -TTGGATCCTCATTTTTGGCC that had at their $5^{\prime}$-ends the restriction sites of $\mathrm{ClaI}$ and BamHI, respectively. The amplified fragment was cloned into the construct CMV-HSVtk-hGM-CSF-pGL3 split with ClaI and BamHI.

The design of such constructions was reported earlier [59].

\section{Cell cultures}

The following cancer cell lines were used: HEK293 (transformed human kidney cells), HT1080 (human fibrosarcoma), A431 (human epidermoid carcinoma), and Calu1 (human epidermoid lung carcinoma) from ECACC (Salisbury, UK), and C26 (murine colon adenocarcinoma) from Cell Lines Service (CLS GmbH, Eppelheim, Germany).

Sarcoma 37, Lewis lung carcinoma (LLC), and cervical squamous carcinoma (CSC5) mouse tumors were obtained from the Department of Tumor Strains of Blokhin RRCO RAMS (Moscow, Russia).

Tumor cell lines LLC, CSC5 и S37 were obtained by culturing dissociated cells from the corresponding transplantable mouse tumors in RPMI 1640 medium.

S37, CSC5 and C26 cell lines were grown in RPMI1640 medium containing $12.5 \%$ fetal calf serum, $60 \mu \mathrm{g} / \mathrm{ml}$ penicillin, $100 \mu \mathrm{g} / \mathrm{ml}$ streptomycin, and $0.25 \mu \mathrm{g} / \mathrm{ml}$ amphotericin at $37^{\circ} \mathrm{C}$ and $5 \% \mathrm{CO}_{2}$.

All other cells were grown in DMEM/F12 medium containing $10 \%$ fetal calf serum, $60 \mu \mathrm{g} / \mathrm{ml}$ penicillin,

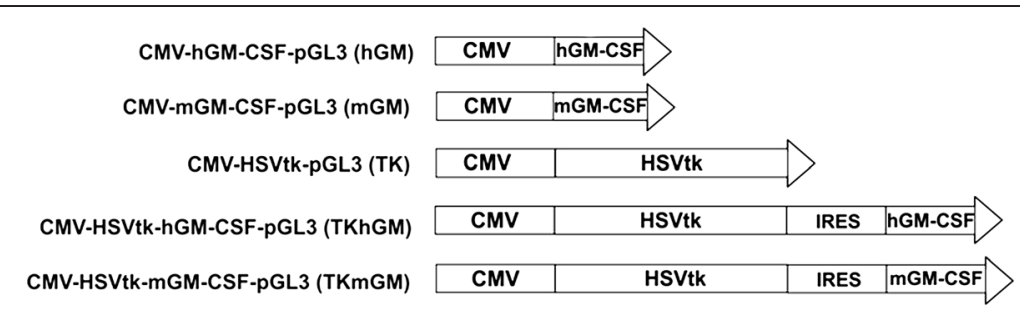

Figure 1 Schematic representation of the expression constructs used. On the left - construct names. The SV40 polyA signal is omitted from the schemes. CMV - major immediate-early promoter of human cytomegalovirus; hGM-CSF and mGM-CSF - human and mouse genes of granulocyte macrophage colony stimulating factor, respectively; HSVtk -herpes simplex virus thymidine kinase gene, IRES - internal ribosome entry site of encephalomyocarditis virus. 
$100 \mu \mathrm{g} / \mathrm{ml}$ streptomycin, and $0.25 \mu \mathrm{g} / \mathrm{ml}$ amphotericin at $37^{\circ} \mathrm{C}$ and $5 \% \mathrm{CO}_{2}$.

All materials for cell culturing were obtained from Invitrogen (Carlsbad, CA, USA).

\section{DNA transfection Lipofection}

For transfection, cells were seeded into 24-well plates or $25-\mathrm{CM}^{3}$ flasks and incubated in serum-containing medium for $24 \mathrm{~h}$. Cells were transfected with Lipofectamine 2000 (Invitrogen, Carlsbad, CA) according to the manufacturer's recommendations. After this, the transfected cells were cultured for $48 \mathrm{~h}$ at $37^{\circ} \mathrm{C}$ and $5 \% \mathrm{CO}_{2}$.

For the GM-CSF protein quantification using ELISA and Western-blot analysis, the transfection was performed in $25-\mathrm{cm}^{3}$ flasks for $48 \mathrm{~h}$.

\section{Transfection with a PEI-PEG-TAT copolymer}

A polyethylenimine (PEI)-polyethylene glycol (PEG)-TAT peptide copolymer (PPT) was obtained as described previously [57]. In this study, the ratio of PEI to PEG in polyplexes was optimized according to [57] to achieve maximum transfection efficiency. A DNA-PPT complex was obtained by vigorous mixing of one volume of a PEI-PEG-TAT copolymer in $0.1 \mathrm{M}$ borate (pH 7.5), one volume of $20 \%$ glucose, 20 MM HEPES buffer (pH 7.4), and two volumes of plasmid DNA water solution (160 $\mu \mathrm{g} / \mathrm{ml} \mathrm{DNA})$. The resulting solution contained $80 \mu \mathrm{g} / \mathrm{ml} \mathrm{DNA}$ and $12.8 \mu \mathrm{g} / \mathrm{ml}$ copolymer. The mixture was incubated for $1-2 \mathrm{~h}$ at room temperature and used for injection into animals in in vivo experiments. Cells were transfected in 24-well plates with the resulting solution 20-40-fold diluted (depending on the cell line) with growth medium and added to wells in a volume of $1 \mathrm{~mL}$ per well. The transfected cells were cultured for $72 \mathrm{~h}$ at $37^{\circ} \mathrm{C}$ and $5 \% \mathrm{CO}_{2}$, and further incubated for $24 \mathrm{~h}$ at $37^{\circ} \mathrm{C}$ and $5 \% \mathrm{CO}_{2}$ after addition of an equal volume of nutrient medium.

All plasmids used for transfection were isolated using an EndoFree Plasmid Maxi Kit (Qiagen, Valencia, CA).

\section{Measurement of transfection efficiency}

To determine transfection efficiency, reporter plasmids carrying the EGFP reporter gene driven by the pCMV immediate early promoter were used. Cells were transfected in 24-well plates with Lipofectamine 2000 (LFA) or PEI-PEG-TAT. In $48 \mathrm{~h}$ after transfection with LFA or $72 \mathrm{~h}$ in the case of PPT, cells were photographed on a Nikon fluorescence microscope $(200 \times$ field $)$ at $395-\mathrm{nm}$ excitation, and the number of fluorescent cells was determined in 10 microscopic fields. Cells were further washed with PBS buffer, detached from the plate surface with trypsin, and suspended in PBS at $10^{6}$ cells per $1 \mathrm{ml}$. The percentage of transfected cells was determined using a fluorescence-activated cell sorter FACS Scan Analyzer
(BD Bioscience, San-Jose, CA). The data were processed using BD CellQuest Pro (BD Bioscience, San-Jose, CA) and WinMDI 2.8 (by Joe Trotter) software. The transfection efficiency was determined as the percentage of cells whose fluorescence intensity exceeded that of nontransfected cells.

\section{In vitro cell sensitivity to ganciclovir}

Transfected cells were detached from the plate surface, seeded into 96-well plate at 1500-2000 cells per well and incubated for $12-18 \mathrm{~h}$ at $37^{\circ} \mathrm{C}$ and $5 \% \mathrm{CO}_{2}$. The wells were then supplemented with ganciclovir Cymevene ${ }^{\circ}$ (F. Hoffman-La Roche Ltd, Switzerland) solution up to final concentrations of $12.5,50$ or $200 \mu \mathrm{M}$, and incubated for $48 \mathrm{~h}$, after which the GCV solution was replaced with a fresh one, and cells were additionally incubated for $48 \mathrm{~h}$. The number of viable cells was determined by the MTS assay according to the protocol (CellTiter $96^{\circ}$ Aqueous One Solution Cell Proliferation Assay, Promega, Madison, WI). The results were expressed as a ratio between the number of viable cells in the plates that contained the drug and their number in the corresponding drug-free controls. Three independent transfections were performed in each experiment.

\section{HSVtk and GM-CSF production by transfected cells}

The transfected cells were lyzed in SDS sample buffer, and proteins were separated on a 10\% SDS-PAGE and transferred into PVDF membranes. A goat polyclonal antiserum against HSVtk (Santa Cruz Biotechnology, Santa Cruz, CA) and donkey anti-goat IgG-horseradish peroxidase conjugates (Santa Cruz, CA, USA) were used to visualize thymidine kinase. Detection of reactive bands was facilitated by using a horseradish peroxidase-linked secondary conjugate and ECL detection reagents (Biorad, USA).

mGM-CSF and hGM-CSF produced by transfected cells were measured by ELISA of culture medium using a commercial kit (R\&D Systems, Minneapolis, MN).

\section{Measurement of the biological activity of hGM-CSF}

The biological activity of hGM-CSF was determined by the ability of hGM-CSF-containing conditioned medium to maintain proliferation of the hGM-CSF-dependent erythroleukemia cell line TF-1 [60].

\section{Measurement of the biological activity of mGM-CSF}

The biological activity of mGM-CSF was estimated by the ability of GM-CSF-containing conditioned medium to initiate differentiation of mouse bone marrow precursor cells. The precursor cells were cultured in medium supplemented with conditioned medium obtained from S37 cells treated with TKmGM-PPT. As a negative control, we used conditioned medium obtained from S37 
cells transfected with a plasmid that carried the HSVtk and mGM-CSF genes without promoter and was complexed with a PPT copolymer. The procedure was performed as described in [61]. The cells were stained with FITC-labeled antibodies (Caltag, Buckingham, UK) specific for F4/80 (a marker of mature macrophages), IA ${ }^{\mathrm{d}}$ (an innate activation marker of macrophages and dendritic cells), and Gr-1 (a marker of granulocytes), or with PE (phykoerythrin)-labeled antibodies against CD86 (a marker of mature dendritic cells). The stained cells were cytofluorometrically analyzed for the presence of differentiated cells.

\section{Ex vivo experiments}

In ex vivo experiments, we used $\mathrm{C} 57 \mathrm{Bl} / 6$ mice (Animal Breeding Facility - Branch of Shemyakin \& Ovchinnikov Institute of Bioorganic Chemistry, Puschino, Moscow Region, Russia) with an initial medium body weight of $19.0 \pm 1.4 \mathrm{~g}$.

LLC cells were transfected with the CMV-HSVtk-pGL3 (designated as TK) and TKmGM constructs, whereas non-transfected cells were used as the control. The transfection was performed for $3 \mathrm{~h}$ at $30 \mu \mathrm{g}$ DNA and $75 \mu \mathrm{l}$ Lipofectamine 2000 (LFA) per $75-\mathrm{cm}^{3}$ flask. In $24 \mathrm{~h}$ after transfection, the transformed and non-transformed LLC cells were detached with $3 \mathrm{ml}$ trypsin per flask, suspended in complete DMEM/F12 medium, washed twice with PBS, and suspended in PBS at $2 \times 10^{6}$ cells $/ \mathrm{ml} .100-\mu \mathrm{l}$ aliquots $\left(2 \times 10^{5}\right.$ cells $)$ of the suspension were subcutaneously injected into the right dorsal flank of animals. Starting from day 6 after inoculation and after the appearance of palpable tumors, tumor size was measured using an electronic caliper.

Tumor volume was calculated using the formula $\mathrm{A}^{*} \mathrm{~B}^{2} / 2$ [62], where $A$ and $B$ is the length and width of the tumor, respectively. An euthanasia criterion was the tumor size that has reached $2000 \mathrm{~mm}^{3}$.

Each test group of animals injected with LLC cells transformed with the TK and TKmGM constructs contained 10 animals. Control groups contained 6 animals and were injected with non-transformed LLC cells. Animals were uniformly divided among the groups according to their weight.

The average size of tumors was calculated as the total tumor volume divided by the number of animals in the group. The measurement was done until the death of the first animal in each group.

Survival rate of mice was determined as the ratio of the number of mice, having no tumor or tumor with a volume less than $2000 \mathrm{~mm}^{3}$, to the total number of mice in the group. The calculations were carried out until the death of the last mouse with tumor.

$5 \mathrm{mg} / \mathrm{ml} \mathrm{GCV}$ in PBS buffer (Invitrogene, Carlsbad, CA, USA) was intraperitoneally injected into animals for
10 days, two times a day in a dose of $75 \mathrm{mg} / \mathrm{kg}$, starting from the second day (48 h) after transplantation of carcinoma cells.

\section{In vivo experiments}

Six- to eight-week-old F1 (C57Bl/6j $\times$ CBA), BDF1, and $\mathrm{BALB} / \mathrm{c}$ mice were obtained from the Research Centre of Biomedical Technologies, RAS. All animal protocols were performed in accordance with the "Guidelines to Carry out Preclinical Trials of Pharmaceuticals" [62], and the experiments were approved by the Bioethical Committee of the Moscow Hertsen Research Institute of Oncology (MHRIO).

In these experiments we used the TK, mGM and TKmGM constructs complexed with the PEI-PEG-TAT copolymer (designated as TK-PPT, mGM-PPT and TKmGM-PPT, respectively) or with LFA (TK-LFA, mGM-LFA and TKmGM-LFA, respectively). In the case of PPT, the animals were injected with a $80 \mu \mathrm{g} / \mathrm{ml}$ DNA and $12.8 \mu \mathrm{g} / \mathrm{ml}$ copolymer solution. For LFA, the injected solution contained $2.5 \mu \mathrm{l}$ LFA per $1 \mu \mathrm{g}$ DNA.

The DNA-PPT/GCV system was injected into animals of the experimental groups at the doses and according to the schedule described in the Results and Discussion section. Control animals were injected with either pure buffer or DNA-PPT and GCV separately at the same doses and according to the same schedule. Each group contained 8-12 animals, and each experiment was repeated in triplicate.

The mouse S37, LLC and cervical squamous carcinoma (CSC5) tumor strains were maintained in syngeneic mice using standard methods. Tumor cells of the $2^{\text {nd }}$ $8^{\text {th }}$ passages were used in vivo. The C26 colon adenocarcinoma cells were maintained using standard protocols.

The tumor cells or tissues were subcutaneously (s.c.) injected into mice at the following doses per mouse: Sarcoma 37 (F1 C57Bl/6j $\times$ CBA mice) $-2 \times 10^{6}$ cells, C26 (BALB/c mice) - $4 \times 10^{4}$ cells, LLC (BDF1 mice) $30 \mathrm{mg}$ of tumor tissue, CSC5 (BDF1 mice) - $20 \mathrm{mg}$ of tumor tissue in $0.1 \mathrm{ml}$ of isotonic $(0.9 \%) \mathrm{NaCl}$ solution. Primary tumors were formed in $90-100 \%$ of animals. They had standard growth patterns, and S37 also had the ability to form metastases.

Evaluation of antitumor and antimetastatic efficacy was based on measuring the tumor volumes of the primary and metastatic nodes, the lifespan of animals and frequency of lymphogenic metastasis in different groups.

The tumor growth delay (TGD, days) was calculated by the formula:

$\mathrm{TGD}=\mathrm{TTE}_{\exp }-\mathrm{TTE}_{\text {cont }}$, where

$\mathrm{TTE}_{\text {exp }}$ and TTE $\mathrm{T}_{\text {cont }}$ are the periods of achieving a certain tumor volume in the experimental and control groups, respectively. The reference tumor volume varied for different tumors from $500 \mathrm{~mm}^{3}$ for $\mathrm{S} 37\left(\mathrm{TGD}_{500}\right)$ to 
$1000 \mathrm{~mm}^{3}$ for CSC5 $\left(\mathrm{TGD}_{1000}\right)$ and $1500 \mathrm{~mm}^{3}$ for C26 $\left(\mathrm{TGD}_{1500}\right)$.

Tumor metastasis inhibition (MI,\%) was calculated by the formula:

$$
M I=\frac{\operatorname{Vmts}(c)-\operatorname{Vmts}(\exp )}{\operatorname{Vmts}(c)} * 100 \% \text {, where }
$$

$V_{m t s} c$ - mean volume of metastatic lymph nodes in the control groups,

$V_{\text {mts }} \exp$ - mean volume of metastatic lymph nodes in the experimental group.

Frequency of lymphogenic metastasis (FLM,\%) was calculated by the formula:

$F L M=\frac{M}{T} * 100 \%$, where

$\mathrm{M}$ - the number of animals in the group that had metastases in lymph nodes,

$\mathrm{T}$ - the total number of animals in the group.

The presence of metastatic tumor cells in the enlarged lymph nodes of tumor bearing mice was proven using histological examination of the dissected tissues. The lymph nodes were dissected at autopsy, measured in three cross dimensions by a caliper, fixed in $10 \%$ neutral buffered formalin, and embedded into paraffin. Tissue sections stained by haematoxylin and eosin were examined.

The increase in lifespan (ILS,\%) was calculated by the formula:

$$
\begin{aligned}
& I L S=\frac{M L S(\exp )-M L S(c)}{M L S(c)} * 100 \% \text {, where } \\
& M L S(\exp )-\text { mean lifespan in the experimental group } \\
& \text { (days), } \\
& M L S(c) \text { - mean lifespan in the control groups (days). }
\end{aligned}
$$

\section{Statistical analysis}

Statistical analysis was performed using Statistical software version 7.0 (StatSoft, Inc.). The statistical significance of differences between groups was estimated using the t-Student test, Fisher's test and the Mann-Whitney U-criterion depending on the number of observations and the distribution of parameter values in the group. The differences were considered significant at $\mathrm{p}<0.05$. Survival data were presented as Kaplan-Meier curves.

\section{Results}

\section{Construction and in vitro properties of IRES vectors for coexpression of the HSVtk and GM-CSF genes}

We constructed a series of expression plasmids in which the human cytomegalovirus (CMV) major immediate-early promoter directed the expression of the single or tandemly linked HSVtk and GM-CSF genes. Since the GM-CSF protein is species-specific, and the efficacy of gene therapeutic constructs was tested in tumor-inoculated animals, we prepared two constructs, one of which contained the mouse gm-csf gene (mGM-CSF) and was designed for model experiments in mice, whereas another one contained human $G M-C S F$ and was designed for testing of toxicity and subsequent clinical trials as well as for comparative analysis of the functional properties of human and mouse GM-CSF containing constructs.

Simultaneous expression of two genes under the control of one promoter was enabled by the insertion of the internal ribosome entry site (IRES) between the genes.

The structure of the vectors constructed is presented in Figure 1. Each vector contained either the single genes or their tandem combination under the control of the CMV promoter.

Transient transfection experiments showed that the expression level of the HSVtk and mouse and human GM-CSF genes within bicistronic expression constructs obtained was close to that in the constructs containing single genes (Additional file 1: Figure S1).

HEK293 cells transfected with the TKhGM construct produced 110 ng hGM-CSF per $10^{6}$ cells a day, whereas transfected with the control plasmid CMV-hGM-CSFpGL3 (designated as hGM) - $115 \mathrm{ng}$, and transfected with TKmGM and CMV-hGM-CSF-pGL3 (designated as mGM) - 182 and 190 ng mGM-CSF, respectively. Conditioned medium obtained from non-transfected cells did not contain GM-CSF indicating that GM-CSF was produced only due to the expression of the GM-CSF gene within the vectors obtained.

Estimations of the HSVtk biological activity revealed that incubation with GCV was equally efficient in killing cells transfected both with TK and TKmGM (Additional file 2: Figure S2).

The human and mouse GM-CSF protein produced by the expression vectors was found to be biologically active (data not shown).

Use of the PEG-PEI-TAT copolymer for delivery of genetic information into cancer cells: comparison with lipofectamine

Transfection of cell lines in vitro was performed using a standard procedure with LFA. However, the use of LFA as part of gene therapeutic systems is limited due to its toxicity and high price.

In this work, we used polyplexes based on polyethylenimine (PEI) conjugated with a heterobifunctional PEG derivative (N-hydroxisuccinimide ester maleimido-PEG24) to make the complex more hydrophilic. To facilitate penetration into cells, the TAT cell-penetrating peptide (GRKKKRRQRC) was attached to the PEI-PEG copolymer $[57,63]$. The efficiency of transfection of cancer cells of different origin with PEG-PEI-TAT (PPT) and LFA was compared using a GFP reporter gene. The percentage of cells transfected using PPT depended on the cell type and was in a range of $25-45 \%$ for S37 cells, $30-40 \%$ for C26, 20-45\% for A431, about 20\% for HT1080, and 5$30 \%$ for LLC cells. For the same cell lines, the transfection 
level using LFA was $60-75,45-65,20-30,40-55$, and about $20 \%$, respectively.

Also, it was shown that in C26, A431 and HT1080 cell lines the cytotoxic effect of the TKhGM-PPT or TKmGM-PPT complex with GCV was weaker than that of TKGM-LFA, whereas in S37 cells the cytotoxic effects of TKGM-PPT and TKGM-LFA were comparable (Additional file 3: Table S1).

It is important to note that the in vivo antitumor efficacies of LFA and PPT deliveries were approximately the same.

Our experiments demonstrated that TGD, the lifespan, MI and FLM were almost equal for TKmGM and TK constructs combined with GCV irrespective of the used delivery system - LFA or PPT (See Additional file 4: Table S2, Additional file 5: Figure S3). The reason of this phenomenon is under investigation, but probably the known enhanced permeability and retention effect [4] is somehow involved.

\section{Ex vivo antitumor efficacy of TK/GCV and TKmGM/GCV}

To evaluate the contribution of GM-CSF to the therapeutic potential of the prepared constructs, the antitumor efficacy of the TK and TKmGM construct was measured ex vivo in C57BI/6 mice. The mice were subcutaneously inoculated with LLC cells transiently transfected with the TK or TKmGM construct using LFA.

We studied 3 groups of mice: a group inoculated with non-transfected LLC cells (group K), a group inoculated with LLC cells transfected with the TK construct (group TK), and a group inoculated with LLC cells transfected with TKmGM (group TKmGM). Then, half of the animals from each group were intraperitoneally injected with GCV solution at a dose of $75 \mathrm{mg} / \mathrm{kg}$ twice a day for 10 days (groups K/GCV, TK/GCV and TKmGM/GCV), whereas the second half were injected with phosphate buffered saline (PBS) as placebo control (groups K/PBS, TK/PBS and TKmGM/PBS).

As seen from Figure 2A, on day 18 of the experiment (the last day when all animals were still alive), the animals inoculated with the TKmGM/GCV or TK/GCV system showed no indications of tumor development. The tumor growth in the group of animals inoculated with the TKmGM/PBS combination was markedly slower than that in the TK/PBS group or control groups, and the difference was statistically significant $(\mathrm{p}<0.05)$. Since the animals inoculated with TKmGM/PBS or TK/PBS received phosphate buffered saline (PBS) instead of GCV, the suppression of tumor growth in the TKmGM/PBS group was most probably due to the presence of the GM-CSF gene. On day 18 of the experiment, the mean tumor volume in the $\mathrm{K} / \mathrm{GCV}$ control group exceeded that in the $\mathrm{K} / \mathrm{PBS}$ control group, however, the difference was not statistically significant $(\mathrm{p}=0.262)$.
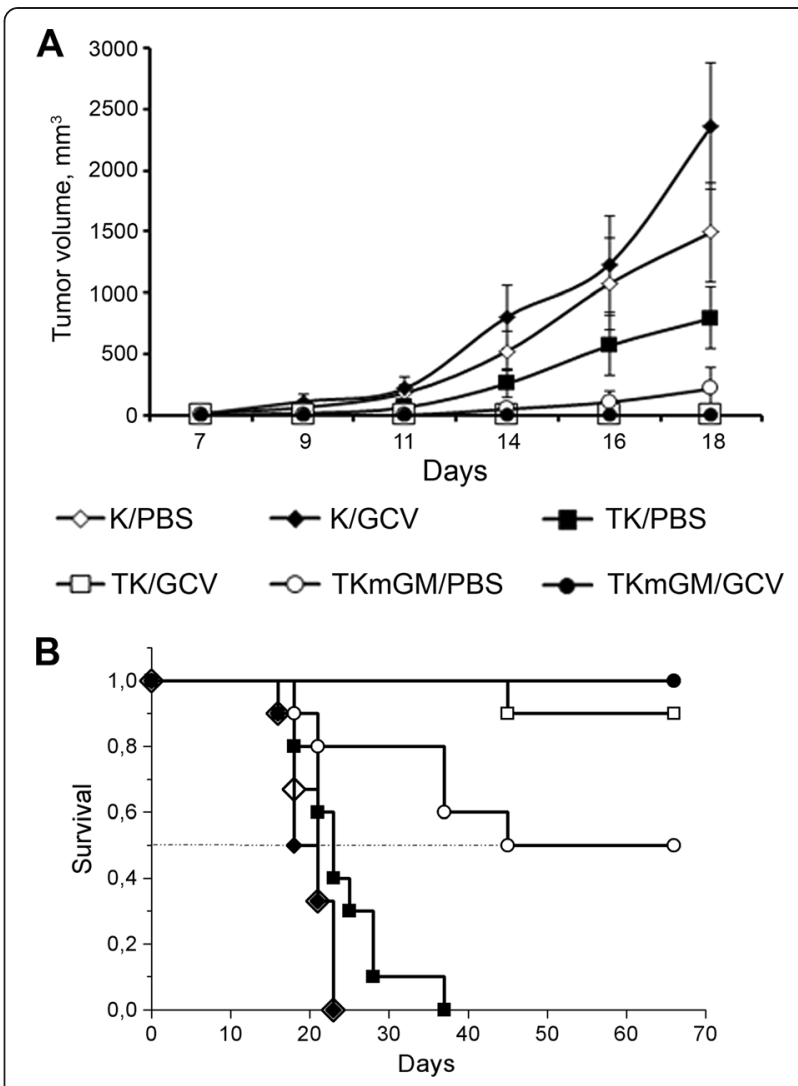

Figure 2 Effect of ex vivo transformation of LLC cells with the TK and TKmGM constructs combined with administration of GCV on A) tumor growth rate, and B) animal lifespan after transplantation of the transfected cells into $\mathrm{C} 57 \mathrm{BI} / 6$ mice.

The data represent mean values for treatment groups of ten animals and control groups of six animals. We studied 6 groups of mice: two control groups (K/GCV and K/PBS) inoculated with non-transfected cells; two experimental groups (TKGGCV and TK/PBS) inoculated with LLC cells transfected with TK; and two experimental groups (TKmGM/ GCV and TKmGM/PBS) inoculated with LLC cells transfected with TKmGM using LFA. The animals of groups K/GCV, TK/GCV and TKmGM/GCV received intraperitoneal injections of ganciclovir in a dose of $75 \mathrm{mg} / \mathrm{kg}$ twice a day for 10 days. The animals of groups K/PBS, TK/PBS and TKmGM/PBS received phosphate buffered saline (PBS) as a placebo instead of GCV. Starting from day 6 after transplantation, we measured the volume of developed tumors. The euthanasia criterion was the tumor volume that exceeded $2000 \mathrm{~mm}^{3}$. A) Tumor volume (in $\mathrm{mm}^{3}, \mathrm{Y}$-axis) versus time since cell transplantation (X-axis). Mean \pm SEM values are shown. B) Survival period of mice after transplantation of the transfected and non-transfected LLC cells.

By the end of the experiment (on day 60), all animals from the TKmGM/GCV group were alive, whereas 10 and $50 \%$ of the animals from the TK/GCV and TKmGM/PBS groups, respectively, have died. All mice of the TK/PBS, PBS, and GCV groups died (Figure 2B). All animals that have survived by day 60 of the experiment did not produce recurrent tumors during an one-year period of observation after the end of the experiment. Thus, both the TK and TKmGM constructs demonstrated antitumor 
effect, although this effect was much more pronounced in the case of TKmGM. This experiment was repeated in triplicate, and in all cases the survival rate in the TKmGM/GCV group was higher than that in the TK/ GCV group.

Similar results were obtained earlier in the work of Castleden et al., where the authors in ex vivo experiments compared antitumor effects of a construct, in which the HSVtk and GM-CSF genes shared a common promoter, and of constructs harboring the single HSVtk or GM-CSF genes [64].

Further comparative analysis of the therapeutic potential of the constructs was performed in vivo in mice.

Tumor growth delay and prolongation of the survival period due to TKmGM-PPT/GCV therapy of tumor-bearing mice We used PEG-PEI-TAT (PPT) copolymers for in vivo delivery of the therapeutic constructs obtained $[57,65]$. We showed that the developed copolymers are nonimmunogenic and can be easily modified for targeted delivery (to be published separately).
The selection of the most efficient therapeutic scheme for the copolymer/DNA polyplexes obtained was done using $\mathrm{F} 1 \mathrm{C} 57 \mathrm{Bl} / 6 \mathrm{j}$ x CBA mice subcutaneously inoculated with sarcoma 37 cells. These cells were characterized by the highest level of transfection with the polyplexes.

The most efficient therapeutic scheme for TKmGM$\mathrm{PPT} / \mathrm{GCV}$ was found to be triple intratumoral injection of TKmGM-PPT at a unit dose of $0.04 \mu \mathrm{g}$ DNA per $1 \mathrm{~mm}^{3}$ tumor volume with 5-day intervals (Table 1A) at the background of GCV injection for 15 days.

\section{Comparison of the antitumor effect of the TK, mGM and TKmGM constructs delivered by PEG-PEI-TAT in mice with sarcoma 37}

Mouse sarcoma 37 cells were subcutaneously inoculated into $\mathrm{F} 1 \mathrm{C} 57 \mathrm{Bl} / 6 \mathrm{j} \times \mathrm{CBA}$ mice. The treatment according to the scheme in Table $1 \mathrm{~A}$ was started on day 7 of tumor growth, when the mean tumor volume was about $100 \mathrm{~mm}^{3}$.

We used polyplex solutions at PPT concentrations in a range of $12.5-25 \mu \mathrm{M}$, because we have earlier shown that

Table 1 Effect of intratumoral administration of various complexes on mice inoculated with sarcoma 37

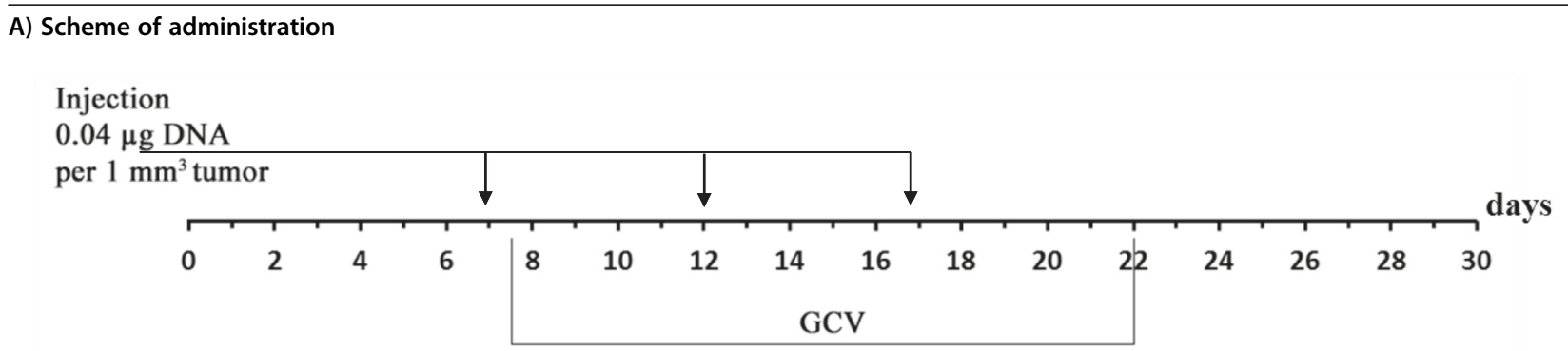

B)

\begin{tabular}{|c|c|c|c|c|c|c|}
\hline Constructs and controls & Lifespan, days & ILS, $\%$ & $\mathrm{TGD}_{500 \mathrm{~mm} 3}$, days & FLM, $\%$ & Volume of lymph nodes, $\mathrm{mm}^{3}$ & $\mathrm{MI}, \%$ \\
\hline TKmGM-PPT/GCV & $60 \pm 22$ & $70^{*}$ & 14.1 & $33^{*}$ & $100 \pm 45$ & $82^{*}$ \\
\hline TK-PPT/GCV & $57 \pm 15$ & $62^{*}$ & 11.6 & $58^{*}$ & $186 \pm 80$ & $67^{*}$ \\
\hline mGM-PPT/GCV & $39 \pm 13$ & 9 & 4.1 & $50^{*}$ & $189 \pm 91$ & 66 \\
\hline TKmGM-PPT/PBS & $41 \pm 7$ & 16 & 3.9 & $42^{*}$ & $298 \pm 264$ & 47 \\
\hline TK-PPT/PBS & $38 \pm 4$ & 8 & 2.6 & 75 & $459 \pm 339$ & 18 \\
\hline mGM-PPT/PBS & $48 \pm 4$ & 35 & 3.0 & $58^{*}$ & $349 \pm 242$ & 38 \\
\hline Control/GCV & $40 \pm 3$ & 6 & 0.3 & 100 & $457 \pm 121$ & 19 \\
\hline Control/PBS & $35 \pm 3$ & - & & 100 & $562 \pm 316$ & \\
\hline
\end{tabular}

F1 (C57BI/6jxCBA) female mice (12 animals in each group) were inoculated with sarcoma 37 on day zero. TKmGM (CMV-HSVtk-mGM-CSF-pGL3 construct), TK (CMV-HSVtk-pGL3), mGM (CMV-mGM-CSF-pGL3); PPT - polyethylenimine-polyethylene glycol-TAT peptide copolymer; PBS - phosphate buffered saline (placebo); GCV - ganciclovir. Control - the group that received only GCV or PBS. Administrations of the complexes are shown by arrows in the scheme. GCV was administered intravenously twice a day with an interval of $12 \mathrm{~h}$ in a daily dose of $150 \mathrm{mg} / \mathrm{kg}$ for 15 days (total dose $2.25 \mathrm{~g} / \mathrm{kg}$ ). ILS -increase in lifespan, TGD -tumor growth delay, FLM - frequency of lymphogenic metastasis, MI -metastasis process inhibition, mean values. ILS, FLM, MI (compared with the control group of animals that received PBS) and the volume of lymph nodes were measured on day 30 after inoculation. The constructs and control solutions were administered intratumorally with a 5-day interval between administrations. PBS was administered in volumes equivalent to the GCV administration scheme. The PPT concentration in injected solutions of the constructs was $25 \mu \mathrm{M}$.

${ }^{*}$ - statistically significant values $(p<0.05)$. 
the results did not depend on the PPT concentration within this range (data not shown).

As seen from Table 1 and Figure 3, intratumoral injections of the TK/GCV or TKmGM/GCV polyplexes had a biologically significant antitumor effect. On day 30 , the extension of animal lifespan in mice treated with TKmGM/ GCV and TK/GCV was as high as 70 and $62 \%$, respectively. The tumor growth delay $\left(\mathrm{TGD}_{500}\right)$ for the combination TKmGM/GCV was 14.1 days, and for the combination TK/GCV - 11.6 days.

At the same time, injection of the mGM/GCV, TKmGM/ PBS, TK/PBS or mGM/PBS combinations without GCV or solely GCV had an insignificant effect on tumor growth and animal lifespan.

\section{Comparison of the antimetastatic effect of the TK, GM and TKmGM constructs delivered by PEG-PEI-TAT in mice with sarcoma 37}

Transplantable mouse sarcoma 37 is characterized by extensive lymphogenic metastasis. According to our observations, popliteal and inguinal lymph nodes are the first to be affected by metastases in a mouse bearing the tumor implanted subcutaneously in a hind paw. The inguinal lymph nodes are preferable for S37 metastasis assessment because the popliteal lymph nodes are often involved into the area of the primary tumor growth.

Progressive growth of S37 tumor in mice was accompanied by an increase in the regional lymph nodes size. The mean volume of the inguinal lymph nodes in normal C57Bl/6j $\times$ CBA mice was found to be $16 \pm 6 \mathrm{~mm}^{3}$. The mean volume of ipsilateral and contralateral lymph

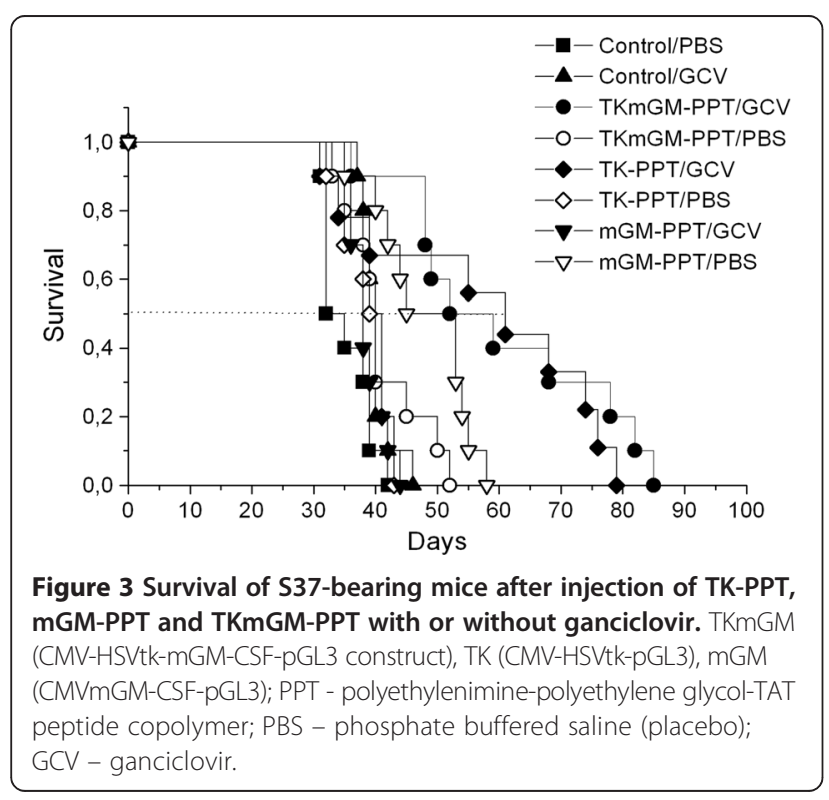

nodes measured on day 35 of the tumor growth in mice bearing subcutaneous S37 tumor varied from 350$500 \mathrm{~mm}^{3}$ to $120-200 \mathrm{~mm}^{3}$, respectively.

The presence of metastatic tumor cells in the enlarged lymph nodes of tumor bearing mice was proven using histological examination of the dissected tissues. The extent of involment of lymph nodes, as a rule, correlated with their size. In the lymph nodes with the volume less than $100 \mathrm{~mm}^{3}$ dissected on day 30-35 after tumor inoculation, the area occupied by metastatic cells usually did not exceed $20 \%$. Microfoci of tumor cells or single tumor cells could be revealed (the estimation was made using serial sections). For the nodes with a $100-250 \mathrm{~mm}^{3}$ volume, the involved section area varied from 20 to $75 \%$. In lymph nodes with a larger volume, metastatic tumor usually completely replaced the lymph node parenchyma. Thus, we consider the volume of inguinal lymph nodes in sarcoma 37 bearing mice a satisfactory and convenient surrogate marker for tumor metastasis assessment.

The total volume of bilateral regional ipsilateral plus contralateral lymph nodes was measured in mice bearing transplanted sarcoma 37. There are two limitations of such a nodes volume-based approach. First, its sensitivity is insufficient to detect early stages of metastasis. Second, the size of the affected lymph nodes does not always correspond to the amount of metastatic tumor cells because of possible reactive changes. Nevertheless, changes in the mean volume of mouse inguinal lymph nodes in the experimental groups directly and strongly correlated with primary S37 tumor growth and lifespan of animals in all our experiments.

The bilateral inguinal lymph nodes of each mouse bearing sarcoma 37 were histologically examined to reveal metastatic involvement at the end of the surveillance period. Histological structure of the primary tumor and typical histological findings in the tissues of dissected lymph nodes are represented in Figure 4 (see a-c, e-g).

It was shown that the volume of lymph nodes in the groups of animals that received TKmGM, TK and mGM polyplexes combined with GCV was much smaller than that in the control group or the comparison groups (Table 1B). The highest metastasis inhibition (82\%) was observed in mice that received TKmGM/GCV, whereas in the case of TK/GCV and mGM/GCV this inhibition was 67 and 66\%, respectively. In the groups of animals treated with the constructs without GCV, metastasis inhibition was observed only for the TKmGM and mGM constructs (47 and 38\%, respectively). This is in line with literature data on the essential role of GM-CSF in metastasis inhibition $[41,64]$. The data obtained demonstrated that the most efficient metastasis inhibition (high MI and low FLM) could be achieved with a combination of the HSVtk and GM-CSF genes within one construct. 


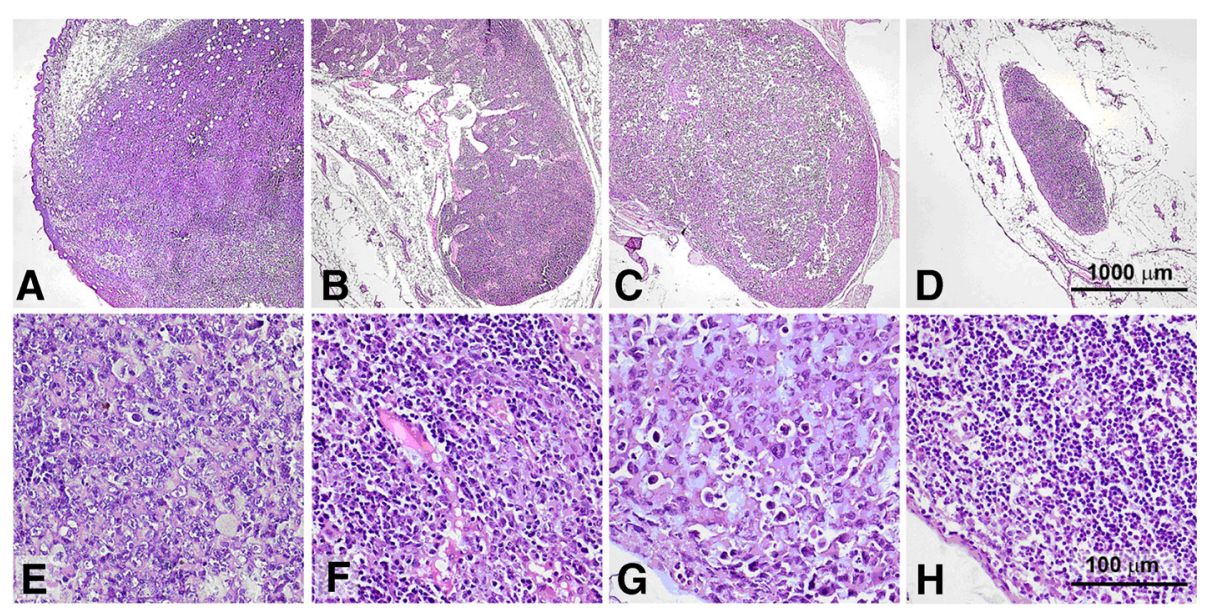

Figure 4 Histological images of tumors and lymph nodes. Subcutaneously transplanted mouse sarcoma 37 on day 15 of tumor growth $(\mathbf{a}, \mathbf{d})$. Metastatic ipsilateral inguinal lymph nodes on the day 30 of tumor growth in control mice $(\mathbf{b}, \mathbf{c}, \mathbf{f}, \mathbf{g})$. Images show tumor cells infiltrating lymph node parenchyma (f) and totally replacing lymph node tissue $\mathbf{( g )}$. A lymph node taken on day 30 after the beginning of the treatment from a mouse treated with TKmGM/GCV (h); note that its parenchyma is free of tumor cells. The sections are made through the largest cross dimension of the tissue samples. Low-power field images (a-d, 40x) demonstrate differences in size between positive (metastatic) and negative (metastasis free) lymph nodes. High-power field images (e-h, 400x) represent detailed histological features of the specimens. Formalin fixed and paraffin embedded tissues (H\&E staining).

\section{Estimation of the in vivo antitumor effect of the TKmGM- PPT/GCV system in different tumors}

The therapeutic potential of the constructs in combination with GCV was evaluated in allograft mouse models inoculated with C26 (murine colon adenocarcinoma) and CSC5 (cervical squamous carcinoma) tumors.

Carcinoma CSC5 tumors were subcutaneously inoculated into $\mathrm{F} 1$ (C57Bl/6j x CBA) mice, and adenocarcinoma of the mouse large intestine (C26) was also subcutaneously inoculated into $\mathrm{BALB} / \mathrm{c}$ mice. The treatment was started on day 7 of tumor growth, when the mean volume of tumor was about $100 \mathrm{~mm}^{3}$. The constructs were injected directly into tumors at a dose of $0.04 \mu \mathrm{g} \mathrm{DNA} / \mathrm{mm}^{3}$ three times with 5-day intervals. GCV was administered for 15 days as intravenous infusions twice a day at a daily dose of $100 \mathrm{mg} / \mathrm{kg}$ for $F_{1}$ mice and $150 \mathrm{mg} / \mathrm{kg}$ for BALB/c mice.

The data obtained showed (Table 2, Figure 5) that treatment with TKmGM-PPT plus GCV had a biologically significant antitumor effect in animals with $\mathrm{C} 26$ tumors. On day 26 in the case of C26 ILS was $42 \%$. $\mathrm{TGD}_{1500}$ in the animals with $\mathrm{C} 26$ was 8.5 days. In the case of CSC5 we observed TGD ${ }_{1000}$ equal to 6 days and a modest or even biologically insignificant extension of animal lifespan (23\%). It may be due to the specific properties of CSC5 tumor or to a non-optimal scheme of treatment for this type of cancer. Injection of constructs without GCV or solely GCV did not appreciably affect tumor growth.

Thus, treatment of sarcoma 37-bearing mice with TKmGM-PPT/GCV according to the scheme used is effective with respect to both the primary tumor focus
(TGD 14.1 days) and metastasis (MI 82\%, at the criterion of 35\%, FLM 33\%) (Table 1, Figure 3). These effects extended the lifespan of mice by $70 \%$ (at the criterion of $35 \%$ ), and the biologically significant antitumor effect persisted for 14 days (at the criterion not less than 7 days). We have also shown that TKmGM-PPT/GCV is efficient for treatment of transplantable tumors $\mathrm{C} 26$ and almost ineffective for CSC5. Thus, the efficacy of TKmGM depends on the histological form of the tumor and declines in the row S37 > C26 > CSC5.

Earlier, it was shown that higher GCV doses enhance therapeutic efficacy of the HSVtk/GCV system [66].

Table 2 Effect of administration of the TKmGM-PPT complex on mice inoculated with $\mathrm{C} 26$ and CSC5 tumors

\begin{tabular}{|c|c|c|c|c|}
\hline \multirow{2}{*}{$\begin{array}{l}\text { Complex or control } \\
\text { solution }\end{array}$} & \multicolumn{2}{|l|}{ C26 } & \multicolumn{2}{|l|}{ CSC5 } \\
\hline & ILS\% & $\mathrm{TGD}_{1500}$ days & ILS\% & $\mathrm{TGD}_{1000}$ days \\
\hline TKmGM-PPT/GCV & 42 & 8.5 & 20 & 6.0 \\
\hline TKmGM-PPT/PBS & -4 & -0.3 & - & - \\
\hline Control/GCV & -12 & 0.8 & 0 & -0.1 \\
\hline Control/PBS & - & - & - & - \\
\hline
\end{tabular}

C26 - female BALB/c mice with C26 tumor (groups of 10 animals), CSC5 female BDF1 mice with CSC5 tumor (groups of 18 animals). Control - the group that received only GCV or PBS. The complexes were administered intratumorally 3 times in a single dose of $0.04 \mu \mathrm{g} \mathrm{DNA} / \mathrm{mm}^{3}$ of tumor volume with a 5-day interval. The first administration was on day 7 of tumor growth. GCV - ganciclovir; GCV was administered for 15 days intraperitoneally twice a day with an interval of $12 \mathrm{~h}$ in a daily dose of $150 \mathrm{mg} / \mathrm{kg}$ (total dose of 2.25 $\mathrm{g} / \mathrm{kg}$ ). ILS -increase in lifespan of mice, TGD -tumor growth delay, MI -metastasis inhibition, mean values, FLM - frequency of lymphogenic metastasis (percentage of animals with metastases in lymph nodes). ILS and MI were measured on day 30 of tumor growth. PBS was administered in volumes equivalent to the GCV administration scheme. 


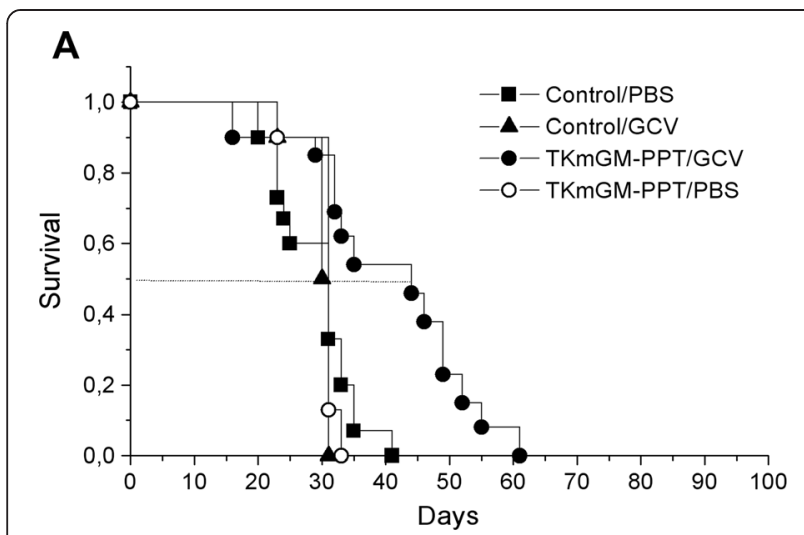

B

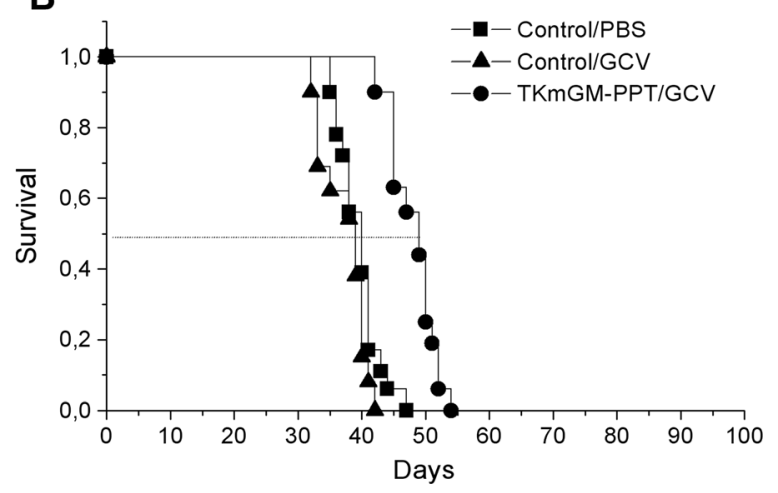

Figure 5 Survival period of mice inoculated with $A$ ) adenocarcinoma C26; B) cervical squamous carcinoma CSC5 after injection of TKmGM-PPT. TKmGM (CMV-HSVtk-mGM-CSF-pGL3 construct); PPT - polyethylenimine-polyethylene glycol-TAT peptide copolymer; PBS - phosphate buffered saline (placebo); GCV - ganciclovir.

Therefore, we have chosen the highest possible daily dose of GCV (150 mg/kg), and TKmGM-PPT was tested in allograft animal models at the background of GCV injection at a daily dose of $150 \mathrm{mg} / \mathrm{kg}$ for 15 days (total dose of $2.25 \mathrm{~g} / \mathrm{kg})$.

\section{Discussion}

We studied the efficacy of the HSVtk/GM-CSF combination in one vector delivered by a nonviral carrier - a PEG-PEI-TAT copolymer. This combination was tested in vitro in various mouse and human cell lines, ex vivo, and in vivo using mouse models. It appeared to be efficient in terms of both tumor shrinkage and metastasis inhibition. The question is whether these results are promising for their further use in clinical practice. The problem in that preclinical efficacy of most drugs in mouse models is not the guarantee of positive clinical response is now widely debated. Even among cancer drugs that have passed Phase I testing, only 1 of 10 was finally approved [67]. Therefore, extrapolation of the results for these models to human disease is often not straightforward $[67,68]$.
We will try to consider this problem from the standpoint of gene therapy prospects with respect to clinical trials.

\section{HSVtk can be active in human tumors providing proper} delivery

HSVtk seems to be a very attractive potential drug due to its universal mechanisms of action. It is targeted at the cell's replication machinery, which exists in all species, thus making HSVtk applicable to any tumor. Recent reports on preclinical cancer models demonstrated a high potential of HSVtk when used in combination with new therapeutic approaches [1]. One of the HSVtk great advantages is the bystander effect that allows to destroy not only cells transfected with the gene but also nearby untransfected cells, thus strongly increasing the potential efficacy $[22,69,70]$. Another potential advantage of HSVtk is its ability to stimulate the immune system to eliminate tumor cells that do not express the suicide gene, a phenomenon which could lead to the destruction of metastases originated from a primary tumor [19]. All these effects are not expected to be species specific. Indeed, we demonstrated that the HSVtk gene was translated into a functional HSVtk enzyme at a high level in human cells. Due to the advantageous features of HSVtk, the HSVtk/GCV was the first GDEPT system described. A large number of experiments were performed with this system in different types of tumors, and initial results in animal models were very promising [71]. However, the clinical trials were not so convincing, although they are still going on $[1,17,19,71-73]$. The barriers on the way of translation of preclinical models to clinical outcomes are most probably due to specific properties of model animal tumors and their microenvironment [74,75]. Apart from other aspects of intra- and inter-tumor variability, many authors pay great attention to a so called enhanced permeability and retention (EPR) phenomenon [4,76-81]. EPR is a property of well-developed and poorly differentiated solid tumor vasculature, the enhanced permeability of which allows nanoparticles of the size of up to several hundreds of nanometers to enter the tumor interstitial space, whereas the suppressed lymphatic filtration allows them to stay there. Now it is becoming clear that the EPR effect is much stronger in mouse tumors than in human patients, simply because most rodent tumors grow much faster. This directly concerns the HSVtk/GCV system which forms nanoparticles both in case of its delivery by viral and nonviral particles.

Moreover, penetration of drugs into the tumor and metastatic cells is hindered due to the properties of the tumor microenvironment. Hence, drug uptake can be different in animal and human tumors. Other peculiarities of intratumoral barriers and the biodistribution of 
drugs were considered in detail in the above cited reviews.

These highly complicated multilayer systems of barriers on the way of a drug to tumor cells stimulate the search for additional means to make tumor and its metastases more vulnerable to therapy. One of such means is activators of the host immune system, such as cytokines [82-84]. We used GM-CSF for this goal.

\section{GM-CSF is a potent immunomodulator both in mice and human: positive practice of its clinical application}

Cytokines are used worldwide in clinical trials for the purposes of cancer gene therapy. The database [85] contains 1264 records devoted to cancer gene therapy clinical trials. 367 (29\%) of them used cytokine genes as therapeutic agents, and 84 utilized GM-CSF. Data on synergistic activity of the suicide gene HSVtk and the immunomodulator GM-CSF support the GM-CSF capacity to enhance therapeutic effect [42]. There is a general belief that although local tumor control is important, efficient therapies to increase survival rate must also target metastases. Clinically, most cancer patients die of relapse and metastasis, and not of the primary tumor. However, the therapeutics capable of effectively preventing and targeting metastasis are very limited $[86,87]$. GM-CSF is considered one of the most effective inducers of tumor immunity [88]. It was reported to be able to enhance most types of immune responses [30]. The GM-CSF recombinant protein (Sargramostim/Leukine) was approved by FDA for clinical use. GM-CSF is extensively used in genetic engineering of (re-)infused cells for vaccination purposes [37].

Many oncolytic viruses armed with GM-CSF are now in clinical trials (see e.g. $[26,32-35,54,89,90])$. The data available permit to hope that GM-CSF will be as effective in cancer patients as in our model systems.

Positive application of oncolytic viruses producing GM-CSF Large tumor volume, cancer and stromal cells differently organized in different locations of the same tumor, and other negative factors [10,91-96] may create difficulties for both suicide and oncolytic virus therapy. This is an important reason for attempting to reach systemic efficacy by recruiting the immune system, instead of relying on oncolysis alone [90].

It has been already reported that several species of oncolytic viruses producing GM-CSF were tested in clinical trials and demonstrated safety, antitumor efficacy, and tumor-specific immune activation [54,90]. It was also shown that oncolytic virus therapies with GM-CSF expressing vectors can induce durable responses even in late stage solid tumors through the direct oncolysis and induction of anticancer immunity [33,34].

A hypothesis was put forward that tumor antigens released from dying cancer cells are accessible to antigen presenting cells which can activate cytotoxic T-lymphocytes for killing non-infected tumor cells $[19,41,90]$. This immune activation can be increased by locally produced GM-CSF, leading eventually to more aggressive antitumor immune response [90]. In case of suicide gene therapy, this hypothesis predicts that a combination of a suicide gene and GM-CSF within one vector will be preferable over a combination of two independent vectors each carrying only one of these two genes. The latter combination was tested earlier [41].

\section{Advantages of nonviral delivery systems}

We used PEI-containing polyplexes modified with polyethylene glycol (PEG) and the cell-penetrating peptide TAT. The properties and behavior of these polyplexes in different cell lines could be adjusted to achieve higher transfection efficiency [57]. A detailed discussion of advantages and disadvantages of viral and nonviral delivery systems in gene therapy can be found in recent reviews $[1,18,19,97-103]$. Briefly, nonviral vectors are advantageous due to low immunogenicity, practically unlimited packaging capacity for genetic material, and simple and low-cost production, which makes them more suitable to large-scale production and potentially safer in clinical use $[56,98,104-106]$. However, they are characterized by low gene transfer efficiency and transient or steadily declining gene expression. On the other hand, viral vectors are characterized by low packaging capacity, relatively high production costs and a toxicity profile that can provoke inflammation and immunogenicity. Potential dangers of viral vectors to patients, staff, and possible shedding into the environment have resulted in rather stringent terms of use and risk assessments. Commercial manufacturing of therapeutic viruses, which is the final goal of research efforts, may meet serious problems and be highly expensive. These features have led to questioning the viability of virus-based approaches [55].

Keeping this in mind, it is interesting to analyze the latest data on GDEPT systems which are now in clinical trials according to the database "Gene therapy. Clinical trials worldwide" provided by the Journal of Gene Medicine [85], updated by July 2013.

According to the database, there are 9 Phase III, 12 Phase II and 91 Phase I ongoing clinical trials for treatment of various cancers with suicide genes in various vectors. Adenoviral, retroviral and herpes simplex type 1 viral vectors were used in 64, 66, and 11 trials, respectively. Only a few trials used inexpensive delivery systems: 5 trials used naked plasmid DNA and two trials lipofection.

Such an evident "viral bias" is in line with the opinion expressed by Duenas-Gonzalez and colleagues: "The highrisk/high-reward aspect of drug discovery comprises a greater issue in the commercial realm in terms of new- 
compound approval and marketability. Therefore, oncological products are subject to the laws of marketing; hence, the majority of the newer cancer products are simply costprohibitive to the vast majority of patients worldwide, which has been widely approached and reviewed" [107].

\section{Conclusions}

Apart from efficacy and safety, it is desirable that each drug should be inexpensive and affordable to a wide range of patients. In present-day GDEPT clinical trials, viral delivery systems dominate due to efficient transfection and production of therapeutic genes. However, safety concerns associated with immune and inflammatory responses as well as high cost of therapeutic viruses can limit their wide therapeutic use. In this regard, nonviral delivery systems seem to be advantageous despite lower efficiency. An important attribute of suicide therapy is the so-called bystander effect, which can partially compensate for the poor efficiency due to the diffusion of intracellular toxin to neighboring tumor cells. A further increase in the efficiency of GDEPT can be achieved by induction of antitumor immune response which should also lead to the destruction of metastases.

Therefore, we designed and experimentally tested nonviral vectors that carried both the suicide (HSVtk) and immunomodulating (GM-CSF) genes encapsulated inside the envelope made of a PEG-PEI-TAT copolymer. The vectors were administered intratumorally. We expected a synergistic effect of the two therapeutic genes because of a high local concentration of both tumor antigens from destroyed cancer cells and the cytokine recruiting immune antigen-presenting cells. In fact, we found that the simultaneous intracellular expression of the HSVtk and GM-CSF genes had a greater antitumor effect than the expression of HSVtk or GM-CSF alone. In particular, the treatment of animals with the TKmGM-PPT system was, in most cases, able to inhibit the growth of tumor and metastases and increase lifespan. Thus, the data obtained here show that quite efficient antitumor effects can be achieved using a simple and low toxic nonviral carrier - a PEG-PEI copolymer, providing that the vector contains both the suicide and immunomodulating gene. Study of the TKmGMPPT toxicity demonstrated safety of this complex. The observed toxic reactions in animals were weak and fully reversible (to be published elsewhere). We believe that the results obtained are promising enough to move towards clinical trials.

Vector constructions used in the work: TKmGM - CMVHSVtk-mGM-CSF-pGL3 construct, TKhGM - CMVHSVtk-hGM-CSF-pGL3 construct, TK - CMV-HSVtk-pGL3 construct, hGM - CMV-hGM-CSF-pGL3 construct, mGM - CMV-mGM-CSF-pGL3 construct, TKGM - collective designation for CMV-HSVtk-mGM-CSF-pGL3 and CMV-HSVtk-hGM-CSF-pGL3 construct.

\section{Additional files}

Additional file 1: Figure S1. Production level of HSVtk expressed from the TK and TKmGM constructs transfected with LFA.

Additional file 2: Figure S2. Biological activity of HSVtk expressed from the TK and TKmGM constructs transfected with LFA.

Additional file 3: Table S1. In vitro cytotoxic effect of TKGM complexed with PPT or LFA, in combination with GCV.

Additional file 4: Table S2. In vivo cytotoxic effect of TK, mGM or TKmGM complexed with PPT or LFA in combination with or without ganciclovir.

Additional file 5: Figure S3. Survival period of sarcoma 37-bearing mice after injection of TK-LFA, mGM-LFA and TKmGM-LFA with or without ganciclovir.

\section{Abbreviations}

5-FC: 5-fluorocytosine; 5-FU: 5-fluorouracil; CD: Cytosine deaminase; EPR: Enhanced permeability and retention effect; FLM: Frequency of lymphogenic metastasis; GCV: Ganciclovir; GDEPT: Gene directed enzyme prodrug gene therapy; GM-CSF: Granulocyte-macrophage colony-stimulating factor; hGM-CSF: Human GM-CSF; mGM-CSF: Mouse GM-CSF; HSVtk: Herpes simplex virus thymidine kinase; IFN- $\gamma$ : Interferon $\gamma$; IL: Interleukin; ILS: Increase in lifespan; IRES: Internal ribosome entry site; LFA: Lipofectamine; MI: Metastasis process inhibition; PBS: Phosphate buffered saline; PEG: Polyethylene glycol; PEl: Polyethylenimine; PPT: Polyethylenimine-polyethylene glycol-TAT peptide copolymer; TGD: Tumor growth delay; TNF-a: Tumor necrosis factor a; TTE: Time to endpoint.

\section{Competing interests}

The authors declare that they have no competing interests.

\section{Authors' contributions}

IVA performed and evaluated the study. EVS, IPC, WP, VKP, AVS, GSM, EPK, YVK, AVU, AAR, OAB, ADP and ERN assisted to perform the study and data analysis. TW, ASS, RIY and EDS participated as principle investigators of the study, and drafted the manuscript. IVA, TW and EDS wrote the manuscript. All authors read and approved the final manuscript.

\section{Acknowledgements}

The authors are grateful to Dr. B. Glotov for critical reading of the manuscript. This work was supported by the program Molecular and cellular biology of Presidium of the Russian Academy of Sciences, the program Leading scientific schools of the Russian Federation NSh 674.2012.4, the State contract № $11411.1008700 .13 .084,2011-2013$ of Ministry of the Industry and Trade of the Russian Federation. The reported study was partially supported by RFBR, research projects \#\# 13-04-40170-H comfi and 13-04-01282-a.

\section{Author details}

${ }^{1}$ Shemyakin-Ovchinnikov Institute of Bioorganic Chemistry, Russian Academy of Sciences, ul. Miklukho-Maklaya 16/10, Moscow 117997, Russia. ${ }^{2}$ Institute of Molecular Genetics, Russian Academy of Sciences, Kurchatov Sq. 2, Moscow 123182, Russia. Institute of Gene Biology, Russian Academy of Sciences, ul. Vavilova, 34/5, Moscow 119334, Russia. ${ }^{4}$ Moscow State University, Biological Faculty, ul. Leninskiye Gory, 1-12, Moscow 119234, Russia. ${ }^{5}$ Moscow Hertsen Research Institute of Oncology, Russian Ministry of Health Care, 2nd Botkinskiy proezd 3, Moscow 125284, Russia.

Received: 21 October 2014 Accepted: 10 February 2015

Published online: 04 March 2015

\section{References}

1. Duarte S, Carle G, Faneca H, de Lima MC, Pierrefite-Carle V. Suicide gene therapy in cancer: where do we stand now? Cancer Lett. 2012;324:160-70.

2. Sverdlov ED. Genetic surgery - a right strategy to attack cancer. Curr Gene Ther. 2011;11:501-31. 
3. Corti A, Pastorino F, Curnis F, Arap W, Ponzoni M, Pasqualini R. Targeted drug delivery and penetration into solid tumors. Med Res Rev. 2011;32:1078-91.

4. Kwon IK, Lee SC, Han B, Park K. Analysis on the current status of targeted drug delivery to tumors. J Control Release. 2012;164:108-14.

5. Ranganathan R, Madanmohan S, Kesavan A, Baskar G, Krishnamoorthy YR, Santosham R, et al. Nanomedicine: towards development of patient-friendly drug-delivery systems for oncological applications. Int J Nanomedicine. 2012;7:1043-60.

6. Li J, Chen F, Cona MM, Feng Y, Himmelreich U, Oyen R, et al. A review on various targeted anticancer therapies. Target Oncol. 2012;7:69-85.

7. Collins SA, Guinn BA, Harrison PT, Scallan MF, O'Sullivan GC, Tangney M. Viral vectors in cancer immunotherapy: which vector for which strategy? Curr Gene Ther. 2008:8:66-78.

8. Loisel-Meyer S, Foley R, Medin JA. Immuno-gene therapy approaches for cancer: from in vitro studies to clinical trials. Front Biosci. 2008;13:3202-14.

9. Podhajcer OL, Lopez MV, Mazzolini G. Cytokine gene transfer for cancer therapy. Cytokine Growth Factor Rev. 2007;18:183-94.

10. Brenner MK, Okur FV. Overview of gene therapy clinical progress including cancer treatment with gene-modified T cells. Hematology Am Soc Hematol Educ Program. 2009;2009:675-81.

11. Dougan M, Dranoff G. Immune therapy for cancer. Annu Rev Immunol. 2009:27:83-117.

12. Vachani A, Moon E, Wakeam E, Haas AR, Sterman DH, Albelda SM. Gene therapy for lung neoplasms. Clin Chest Med. 2011;32:865-85.

13. McCormick F. Cancer gene therapy: fringe or cutting edge? Nat Rev Cancer. 2001;1:130-41.

14. Ardiani A, Johnson AJ, Ruan H, Sanchez-Bonilla M, Serve K, Black ME. Enzymes to die for: exploiting nucleotide metabolizing enzymes for cancer gene therapy. Curr Gene Ther. 2012;12:77-91.

15. Xu J, Jin C, Hao S, Luo G, Fu D. Pancreatic cancer: gene therapy approaches and gene delivery systems. Expert Opin Biol Ther. 2010;10:73-88.

16. Hattori Y. Development of nonviral vector for cancer gene therapy. Yakugaku Zasshi. 2010;130:917-23.

17. Zarogoulidis P, Darwiche K, Sakkas A, Yarmus L, Huang H, Li Q, et al. Suicide gene therapy for cancer - current strategies. J Genet Syndr Gene Ther. 2013;4:16849.

18. Malecki M. Frontiers in suicide gene therapy of cancer. J Genet Syndr Gene Ther. 2012;3:e114.

19. Portsmouth D, Hlavaty J, Renner M. Suicide genes for cancer therapy. Mol Aspects Med. 2007;28:4-41.

20. van Dillen IJ, Mulder NH, Vaalburg W, de Vries EF, Hospers GA. Influence of the bystander effect on HSV-tk/GCV gene therapy. A review Curr Gene Ther. 2002;2:307-22.

21. Mesnil M, Yamasaki H. Bystander effect in herpes simplex virus-thymidine kinase/ganciclovir cancer gene therapy: role of gap-junctional intercellular communication. Cancer Res. 2000:60:3989-99.

22. Dachs GU, Hunt MA, Syddall S, Singleton DC, Patterson AV. Bystander or no bystander for gene directed enzyme prodrug therapy. Molecules. 2009;14:4517-45.

23. Khatri A, Zhang B, Doherty E, Chapman J, Ow K, Pwint H, et al. Combination of cytosine deaminase with uracil phosphoribosyl transferase leads to local and distant bystander effects against RM1 prostate cancer in mice. J Gene Med. 2006;8:1086-96

24. Preuss E, Muik A, Weber K, Otte J, von Laer D, Fehse B. Cancer suicide gene therapy with TK.007: superior killing efficiency and bystander effect. J Mol Med (Berl). 2011;89:1113-24.

25. Slavcev R, Wettig $S$, Kaur T. Nanomedicine based approaches to cancer diagonsis and therapy, nonviral gene therapy. In: Yuan $X$, editor. Nonviral gene therapy. Rijeka, Croatia: InTech Open Access Publisher; 2011. p. 515-46.

26. Cerullo V, Pesonen S, Diaconu I, Escutenaire S, Arstila PT, Ugolini M, et al. Oncolytic adenovirus coding for granulocyte macrophage colony-stimulating factor induces antitumoral immunity in cancer patients. Cancer Res. 2010;70:4297-309.

27. Niculescu-Duvaz I, Springer CJ. Introduction to the background, principles, and state of the art in suicide gene therapy. Mol Biotechnol. 2005;30:71-88.

28. Candido J, Hagemann T. Cancer-related inflammation. J Clin Immunol, 2013;33 Suppl 1:S79-84.

29. Hallett MA, Venmar KT, Fingleton B. Cytokine stimulation of epithelial cancer cells: the similar and divergent functions of IL-4 and IL-13. Cancer Res. 2012;72:6338-43

30. Berzofsky JA, Terabe M, Wood LV. Strategies to use immune modulators in therapeutic vaccines against cancer. Semin Oncol. 2012;39:348-57.
31. Pesonen S, Kangasniemi L, Hemminki A. Oncolytic adenoviruses for the treatment of human cancer: focus on translational and clinical data. Mol Pharm. 2011;8:12-28.

32. Grossardt C, Engeland CE, Bossow S, Halama N, Zaoui K, Leber MF, et al. Granulocyte-macrophage colony-stimulating factor-armed oncolytic measles virus is an effective therapeutic cancer vaccine. Hum Gene Ther. 2013;24:644-54.

33. Burke JM, Lamm DL, Meng MV, Nemunaitis JJ, Stephenson JJ, Arseneau JC, et al. A first in human phase 1 study of CG0070, a GM-CSF expressing oncolytic adenovirus, for the treatment of nonmuscle invasive bladder cancer. J Urol. 2012;188:2391-7.

34. Senzer NN, Kaufman HL, Amatruda T, Nemunaitis M, Reid T, Daniels G, et al. Phase II clinical trial of a granulocyte-macrophage colony-stimulating factor-encoding, second-generation oncolytic herpesvirus in patients with unresectable metastatic melanoma. J Clin Oncol. 2009;27:5763-71.

35. Hu JC, Coffin RS, Davis CJ, Graham NJ, Groves N, Guest PJ, et al. A phase I study of OncoVEXGM-CSF, a second-generation oncolytic herpes simplex virus expressing granulocyte macrophage colony-stimulating factor. Clin Cancer Res. 2006;12:6737-47.

36. Gupta R, Emens LA. GM-CSF-secreting vaccines for solid tumors: moving forward. Discov Med. 2010;10:52-60.

37. Vacchelli E, Galluzzi L, Eggermont A, Galon J, Tartour E, Zitvogel L, et al. Trial watch: immunostimulatory cytokines. Oncoimmunology. 2012;1:493-506.

38. Zhang SN, Choi IK, Huang JH, Yoo JY, Choi KJ, Yun CO. Optimizing DC vaccination by combination with oncolytic adenovirus coexpressing $\mathrm{IL}-12$ and GM-CSF. Mol Ther. 2011;19:1558-68.

39. Brockstedt DG, Diagana M, Zhang Y, Tran K, Belmar N, Meier M, et al. Development of anti-tumor immunity against a non-immunogenic mammary carcinoma through in vivo somatic GM-CSF, IL-2, and HSVtk combination gene therapy. Mol Ther. 2002;6:627-36.

40. Majumdar AS, Zolotorev A, Samuel S, Tran K, Vertin B, Hall-Meier M, et al. Efficacy of herpes simplex virus thymidine kinase in combination with cytokine gene therapy in an experimental metastatic breast cancer model. Cancer Gene Ther. 2000;7:1086-99.

41. Jones RK, Pope IM, Kinsella AR, Watson AJ, Christmas SE. Combined suicide and granulocyte-macrophage colony-stimulating factor gene therapy induces complete tumor regression and generates antitumor immunity. Cancer Gene Ther. 2000;7:1519-28.

42. Lee KH, Piao H, Son BR, Heo DS, Kim NK, Kim ST. Herpes simplex virus thymidine kinase and granulocyte macrophage colony-stimulating factor combination gene therapy in a murine CT26 cell colon cancer model. Cancer Gene Ther. 2004;11:570-6.

43. Ostrand-Rosenberg S, Sinha P, Beury DW, Clements VK. Cross-talk between Myeloid-Derived Suppressor Cells (MDSC), macrophages, and dendritic cells enhances tumor-induced immune suppression. Semin Cancer Biol. 2012:22:275-81.

44. Lu T, Gabrilovich DI. Molecular pathways: tumor-infiltrating myeloid cells and reactive oxygen species in regulation of tumor microenvironment. Clin Cancer Res. 2012;18:4877-82.

45. Kao J, Ko EC, Eisenstein S, Sikora AG, Fu S, Chen SH. Targeting immune suppressing myeloid-derived suppressor cells in oncology. Crit Rev Oncol Hematol. 2011;77:12-9.

46. Bayne $\sqcup$, Beatty GL, Jhala N, Clark CE, Rhim AD, Stanger BZ, et al. Tumor-derived granulocyte-macrophage colony-stimulating factor regulates myeloid inflammation and T cell immunity in pancreatic cancer. Cancer Cell. 2012;21:822-35.

47. Gutschalk CM, Yanamandra AK, Linde N, Meides A, Depner S, Mueller MM. GM-CSF enhances tumor invasion by elevated MMP-2, -9 , and -26 expression. Cancer Med. 2013;2:117-29.

48. Pylayeva-Gupta Y, Lee KE, Hajdu CH, Miller G, Bar-Sagi D. Oncogenic Kras-induced GM-CSF production promotes the development of pancreatic neoplasia. Cancer Cell. 2012;21:836-47.

49. Parato KA, Breitbach CJ, Le Boeuf F, Wang J, Storbeck C, Ilkow C, et al. The oncolytic poxvirus JX-594 selectively replicates in and destroys cancer cells driven by genetic pathways commonly activated in cancers. Mol Ther. 2012;20:749-58.

50. Kim JH, Oh JY, Park BH, Lee DE, Kim JS, Park HE, et al. Systemic armed oncolytic and immunologic therapy for cancer with JX-594, a targeted poxvirus expressing GM-CSF. Mol Ther. 2006;14:361-70.

51. Lei N, Shen FB, Chang JH, Wang L, Li H, Yang C, et al. An oncolytic adenovirus expressing granulocyte macrophage colony-stimulating factor shows improved specificity and efficacy for treating human solid tumors. Cancer Gene Ther. 2009;16:33-43. 
52. Lee JH, Roh MS, Lee YK, Kim MK, Han JY, Park BH, et al. Oncolytic and immunostimulatory efficacy of a targeted oncolytic poxvirus expressing human GM-CSF following intravenous administration in a rabbit tumor model. Cancer Gene Ther. 2009;2:73-9.

53. Malhotra S, Kim T, Zager J, Bennett J, Ebright M, D'Angelica M, et al. Use of an oncolytic virus secreting GM-CSF as combined oncolytic and immunotherapy for treatment of colorectal and hepatic adenocarcinomas. Surgery. 2007;141:520-9.

54. Kanerva A, Nokisalmi P, Diaconu I, Koski A, Cerullo V, Liikanen I, et al. Antiviral and antitumor T-cell immunity in patients treated with GM-CSFcoding oncolytic adenovirus. Clin Cancer Res. 2013;19:2734-44.

55. Prestwich RJ, Errington F, Harrington KJ, Pandha HS, Selby P, Melcher A. Oncolytic viruses: do they have a role in anti-cancer therapy? Clinical Medicine oncology. 2008;2008:83-96.

56. Yue $Y$, Wu C. Progress and perspectives in developing polymeric vectors for in vitro gene delivery. Biomaterials Science. 2013;1:152-70.

57. Ulasov AV, Khramtsov YV, Trusov GA, Rosenkranz AA, Sverdlov ED, Sobolev AS. Properties of PEl-based polyplex nanoparticles that correlate with their transfection efficacy. Mol Ther. 2011;19:103-12.

58. Mityaev MV, Kopantzev EP, Buzdin AA, Vinogradova TV, Sverdlov ED. Functional significance of a putative sp1 transcription factor binding site in the survivin gene promoter. Biochemistry (Mosc). 2008;73:1183-91.

59. Alekseenko IV, Kopantzev EP, Vinogradova TV, Sverdlov ED. Bicistronic vector for combined expression of the HSVtk killer gene and cytokine GM-CSF gene in cancer cells. Dokl Biochem Biophys. 2011;439:174-7.

60. Kitamura T, Tange T, Terasawa T, Chiba S, Kuwaki T, Miyagawa K, et al. Establishment and characterization of a unique human cell line that proliferates dependently on GM-CSF, IL-3, or erythropoietin. J Cell Physiol. 1989:140:323-34.

61. Inaba K, Inaba M, Romani N, Aya H, Deguchi M, Ikehara S, et al. Generation of large numbers of dendritic cells from mouse bone marrow cultures supplemented with granulocyte/macrophage colony-stimulating factor. J Exp Med. 1992;176:1693-702.

62. Mironov A, Bunatian N, Vasyliev A, Varstakova O, Zhuravleva M, Lepahin V, et al. Guidelines for conducting preclinical tests of pharmaceuticals. Moscow, Russia; Part One: Grif \& Co Publisher; 2012. In Russian.

63. Rudolph C, Plank C, Lausier J, Schillinger U, Muller RH, Rosenecker J. Oligomers of the arginine-rich motif of the HIV-1 TAT protein are capable of transferring plasmid DNA into cells. J Biol Chem. 2003;278:11411-8.

64. Castleden SA, Chong H, Garcia-Ribas I, Melcher AA, Hutchinson G, Roberts B, et al. A family of bicistronic vectors to enhance both local and systemic antitumor effects of HSVtk or cytokine expression in a murine melanoma model. Hum Gene Ther. 1997:8:2087-102.

65. Kleemann E, Neu M, Jekel N, Fink L, Schmehl T, Gessler T, et al. Nano-carriers for DNA delivery to the lung based upon a TAT-derived peptide covalently coupled to PEG-PEI. J Control Release. 2005;109:299-316.

66. Wang Y, Xu HX, Lu MD, Tang Q. Expression of thymidine kinase mediated by a novel nonviral delivery system under the control of vascular endothelial growth factor receptor 2 promoter selectively kills human umbilical vein endothelial cells. World J Gastroenterol. 2008;14:224-30.

67. Robles Al, Varticovski L. Harnessing genetically engineered mouse models for preclinical testing. Chem Biol Interact. 2008;171:159-64.

68. Singh $M$, Murriel $C L$, Johnson L. Genetically engineered mouse models: closing the gap between preclinical data and trial outcomes. Cancer Res. 2012;72:2695-700.

69. Dachs GU, Tupper J, Tozer GM. From bench to bedside for gene-directed enzyme prodrug therapy of cancer. Anticancer Drugs. 2005;16:349-59.

70. Gagandeep S, Brew R, Green B, Christmas SE, Klatzmann D, Poston GJ, et al. Prodrug-activated gene therapy: involvement of an immunological component in the "bystander effect". Cancer Gene Ther. 1996;3:83-8.

71. Fillat C, Carrio M, Cascante A, Sangro B. Suicide gene therapy mediated by the Herpes Simplex virus thymidine kinase gene/Ganciclovir system: fifteen years of application. Curr Gene Ther. 2003;3:13-26.

72. Kwiatkowska A, Nandhu MS, Behera P, Chiocca EA, Viapiano MS. Strategies in gene therapy for glioblastoma. Cancers (Basel). 2013;5:1271-305.

73. Ginn SL, Alexander IE, Edelstein ML, Abedi MR, Wixon J. Gene therapy clinical trials worldwide to 2012 - an update. J Gene Med. 2013;15:65-77.

74. Rangarajan A, Weinberg RA. Opinion: comparative biology of mouse versus human cells: modelling human cancer in mice. Nat Rev Cancer. 2003;3:952-9.

75. Greek R, Menache A. Systematic reviews of animal models: methodology versus epistemology. Int J Med Sci. 2013;10:206-21.
76. Greek R, Hansen LA. Questions regarding the predictive value of one evolved complex adaptive system for a second: exemplified by the SOD1 mouse. Prog Biophys Mol Biol. 2013;113:231-53.

77. Lammers T, Kiessling F, Hennink WE, Storm G. Drug targeting to tumors: principles, pitfalls and (pre-) clinical progress. J Control Release. 2012;161:175-87.

78. Maeda H, Nakamura H, Fang J. The EPR effect for macromolecular drug delivery to solid tumors: improvement of tumor uptake, lowering of systemic toxicity, and distinct tumor imaging in vivo. Adv Drug Deliv Rev. 2013;65:71-9.

79. Fang J, Nakamura $H$, Maeda $H$. The EPR effect: unique features of tumor blood vessels for drug delivery, factors involved, and limitations and augmentation of the effect. Adv Drug Deliv Rev. 2011;63:136-51.

80. Prabhakar U, Maeda H, Jain RK, Sevick-Muraca EM, Zamboni W, Farokhzad $\mathrm{OC}$, et al. Challenges and key considerations of the enhanced permeability and retention effect for nanomedicine drug delivery in oncology. Cancer Res. 2013;73:2412-7.

81. Durymanov MO, Slastnikova TA, Kuzmich Al, Khramtsov YV, Ulasov AV, Rosenkranz AA, et al. Microdistribution of MC1R-targeted polyplexes in murine melanoma tumor tissue. Biomaterials. 2013;34:10209-16.

82. Zhang T, Hamada K, Hyodo M, Itoh H, Tani K, Goda H, et al. Gene therapy for oral squamous cell carcinoma with IAI.3B promoter-driven oncolytic adenovirus-infected carrier cells. Oncol Rep. 2011;25:795-802.

83. Vanneman M, Dranoff G. Combining immunotherapy and targeted therapies in cancer treatment. Nat Rev Cancer. 2012;12:237-51.

84. Wei F, Wang H, Zhang J, Chen X, Li C, Huang Q. Pharmacokinetics of combined gene therapy expressing constitutive human GM-CSF and hyperthermia-regulated human IL-12. J Exp Clin Cancer Res. 2013;32:5.

85. Gene therapy. Clinical trials worldwide. J Gene Med. 2014 [http://www.wiley. com//legacy/wileychi/genmed/clinical]

86. Zhou Y, Kopecek J. Biological rationale for the design of polymeric anti-cancer nanomedicines. J Drug Target. 2013;21:1-26.

87. Rosel D, Brabek J, Vesely P, Fernandes M. Drugs for solid cancer: the productivity crisis prompts a rethink. Onco Targets Ther. 2013;6:767-77.

88. Tuting T. T cell immunotherapy for melanoma from bedside to bench to barn and back: how conceptual advances in experimental mouse models can be translated into clinical benefit for patients. Pigment Cell Melanoma Res. 2012;26:441-56.

89. Thorne SH. The role of GM-CSF in enhancing immunotherapy of cancer. Immunotherapy. 2013;5:817-9.

90. Pesonen S, Diaconu I, Cerullo V, Escutenaire S, Raki M, Kangasniemi L, et al. Integrin targeted oncolytic adenoviruses Ad5-D24-RGD and Ad5-RGD-D24GMCSF for treatment of patients with advanced chemotherapy refractory solid tumors. Int J Cancer. 2012;130:1937-47.

91. Jang SH, Wientjes MG, Lu D, Au JL. Drug delivery and transport to solid tumors. Pharm Res. 2003;20:1337-50.

92. Lankelma J, Dekker H, Luque FR, Luykx S, Hoekman K, van der Valk P, et al. Doxorubicin gradients in human breast cancer. Clin Cancer Res. 1999;5:1703-7.

93. Tredan O, Galmarini CM, Patel K, Tannock IF. Drug resistance and the solid tumor microenvironment. J Natl Cancer Inst. 2007;99:1441-54.

94. Tannock IF, Lee CM, Tunggal JK, Cowan DS, Egorin MJ. Limited penetration of anticancer drugs through tumor tissue: a potential cause of resistance of solid tumors to chemotherapy. Clin Cancer Res. 2002;8:878-84.

95. Kyle AH, Huxham LA, Yeoman DM, Minchinton Al. Limited tissue penetration of taxanes: a mechanism for resistance in solid tumors. Clin Cancer Res. 2007;13:2804-10.

96. Hambley TW, Hait WN. Is anticancer drug development heading in the right direction? Cancer Res. 2009:69:1259-62.

97. Flotte TR. Gene therapy: the first two decades and the current state-of-theart. J Cell Physiol. 2007;213:301-5.

98. Ohlfest JR, Freese AB, Largaespada DA. Nonviral vectors for cancer gene therapy: prospects for integrating vectors and combination therapies. Curr Gene Ther. 2005;5:629-41.

99. Templeton NS. Nonviral delivery for genomic therapy of cancer. World J Surg. 2009;33:685-97.

100. Zhang $Y$, Satterlee A, Huang L. In vivo gene delivery by nonviral vectors: overcoming hurdles? Mol Ther. 2012;20:1298-304.

101. Lee WY, Zhang T, Lau CP, Wang CC, Chan KM, Li G. Immortalized human fetal bone marrow-derived mesenchymal stromal cell expressing suicide gene for anti-tumor therapy in vitro and in vivo. Cytotherapy. 2013;15:1484-97.

102. Altaner C. Prodrug cancer gene therapy. Cancer Lett. 2008;270:191-201. 
103. Seth P. Vector-mediated cancer gene therapy: an overview. Cancer Biol Ther. 2005;4:512-7.

104. Halama A, Kulinski M, Librowski T, Lochynski S. Polymer-based nonviral gene delivery as a concept for the treatment of cancer. Pharmacol Rep. 2009;61:993-9.

105. Lam P, Khan G, Stripecke R, Hui KM, Kasahara N, Peng KW, et al. The innovative evolution of cancer gene and cellular therapies. Cancer Gene Ther. 2013:20:141-9.

106. Louise C. Nonviral vectors. Methods Mol Biol. 2006;333:201-26.

107. Duenas-Gonzalez A, Garcia-Lopez P, Herrera LA, Medina-Franco JL,

Gonzalez-Fierro A, Candelaria M. The prince and the pauper. A tale of anticancer targeted agents. Mol Cancer. 2008;7:82.

\section{Submit your next manuscript to BioMed Central} and take full advantage of:

- Convenient online submission

- Thorough peer review

- No space constraints or color figure charges

- Immediate publication on acceptance

- Inclusion in PubMed, CAS, Scopus and Google Scholar

- Research which is freely available for redistribution 